\title{
Chain of migrating ureteral calculi: a cat and mouse game
}

\author{
Rahul Janak Sinha, Siddharth Pandey, Deepanshu Sharma, Vishwajeet Singh
}

Urology, King George's Medical University, Lucknow, Uttar Pradesh, India

Correspondence to Dr Siddharth Pandey, sid1420@gmail.com

Accepted 7 December 2018

\section{DESCRIPTION}

A 48-year-old man presented to us with intermittent left flank pain for 3 months, and the present episode was intractable. An ultrasound (US) was done that was suggestive of multiple calculi in the left mid-ureter with dilatation of the ureter proximal to them and a moderate dilatation of the left renal pelvicalyceal system with a parenchymal thickness of $0.8 \mathrm{~cm}$ along with right renal calculus of $1.8 \mathrm{~cm}$. A plain X-ray kidney-ureter-bladder (KUB) was suggestive of a $2.5 \mathrm{~cm}$ calculus in the mid-ureter along with seven secondary calculi proximal to it (figure 1). He had no history of previous surgery or extracorporeal shock wave lithotripsy (ESWL). An attempt was made to place a JJ-stent but even a guide-wire could not be negotiated beyond the impacted ureteric calculus. Thus a US-guided percutaneous nephrostomy (PCN) was placed. Both these procedures were attempted under local anaesthesia. In the subsequent X-ray KUB, four stones had migrated proximally (one in

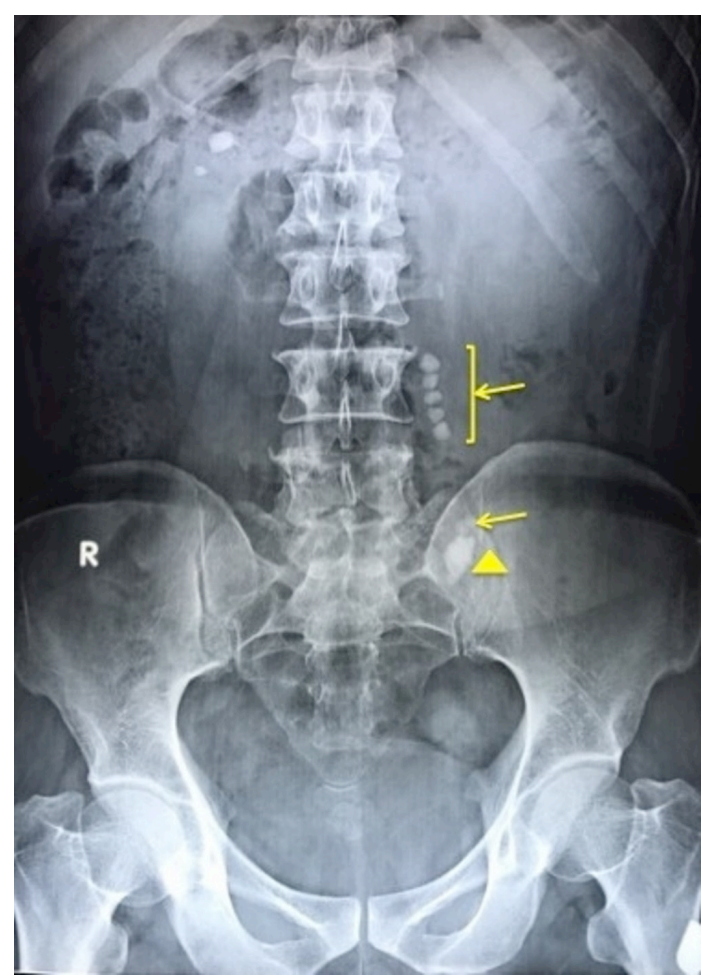

Figure 1 A plain X-ray kidney-ureter-bladder showing the obstructing mid-ureteric calculus (arrow head) with five secondary calculi proximal to it (arrow). The arrows point sexondary calculi while arrowhead points to the primary impacted calculus.

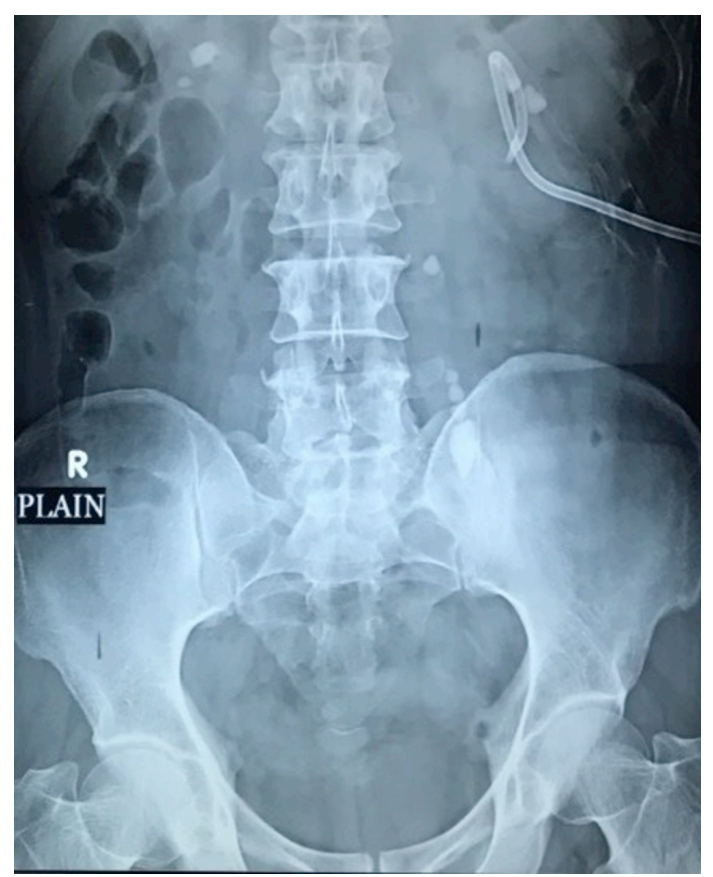

Figure 2 A plain X-ray kidney-ureter-bladder showing the migratory secondary calculi.

the upper ureter and three into the kidney), and it was apparent that the secondary calculi were travelling like a mouse in the dilated upper tract with positional changes (figure 2). After 2 weeks, the output from the PCN was $\sim 1$ L per 24 hours so a renal scan was not done. A nephrostogram was carried out that showed the dilated urinary tract proximal to the obstructing ureteric calculi (figure 3 ). As there was a large impacted calculus with multiple secondary calculi proximal to it, a decision to go for an open or laparoscopic approach rather than an endourological procedure was made. The patient was a smoker with chronic obstructive pulmonary disease and thus was deemed unfit for general anaesthesia. $\mathrm{He}$ did not have any other comorbidity. Hence, after proper consent and counselling, an open ureterolithotomy under spinal anaesthesia was performed. The biggest challenge in this case was to achieve complete clearance with a single incision as the calculi were migratory. Certain precautions were taken. First, we kept the patient in a reverse-Trendelenburg position with $30^{\circ}$ tilt. The surgery lasted around $45 \mathrm{~min}$, and the patient was kept in reverse-Trendelenburg position for around $35 \mathrm{~min}$. Second, the dissection was gentle so that we do not inadvertently up-migrate the calculi. Third, after making the 


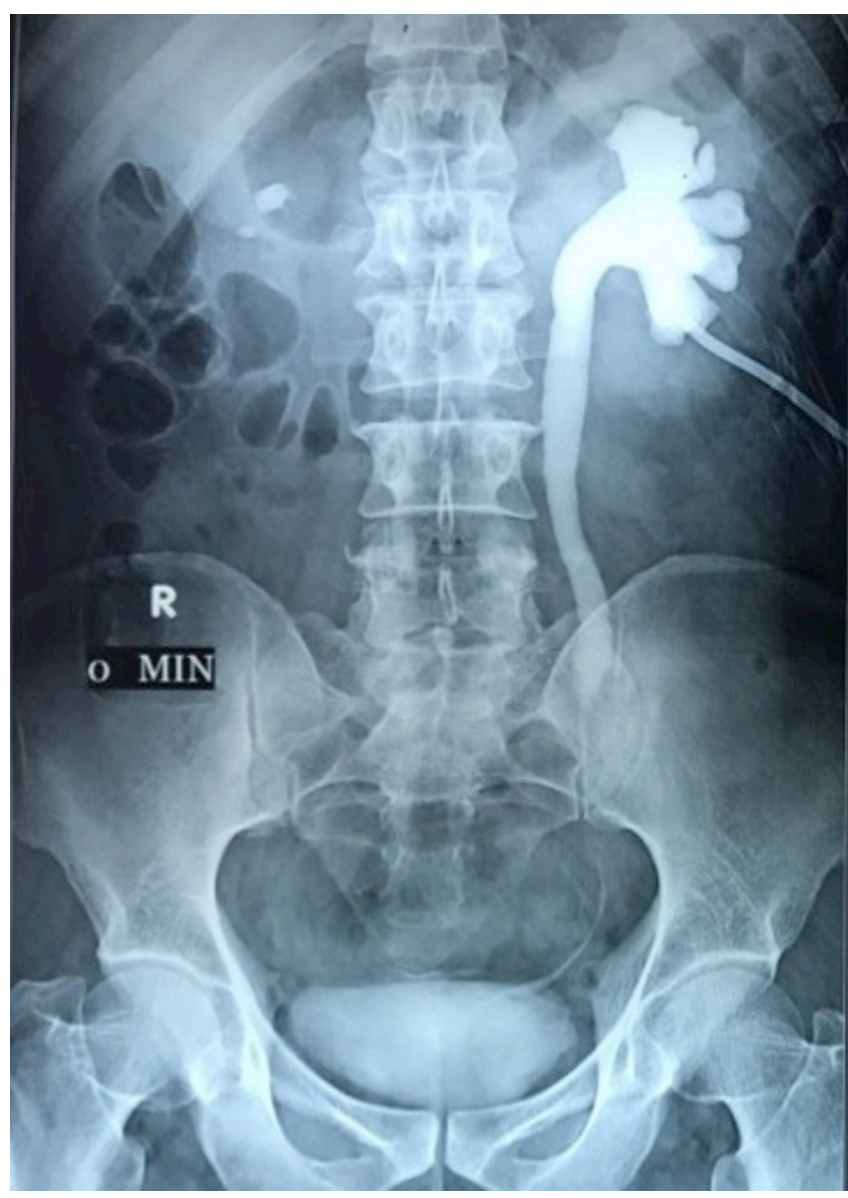

Figure 3 Nephrostogram demonstrating the dilated urinary tract proximal to the obstructing ureteric calculi.

ureterotomy over the impacted calculus for stone retrieval, we started irrigation from the PCN we had placed previously, which aided in down-migration of the calculi that were proximal and thus retrieval from the same ureter incision. The stone-free status was checked on a C-arm intraoperatively. A JJ-stent was placed after retrieving the calculi. The patient fared well, and the postoperative X-ray KUB showed complete clearance of left-sided calculi. The PCN was removed on the second day, and the JJ-stent was removed 2 weeks later. The patient also had calculus in the right kidney for which percutaneous nephrolithotomy was done 2 weeks after the first surgery. Figure 4 shows the $\mathrm{X}$-ray KUB after both surgeries with complete clearance of stones.

For the diagnosis of ureteric calculus, US has a sensitivity of $45 \%$ and specificity of $94 \%$. Usually, therefore an X-ray KUB or non-contrast CT is required along with US for confirming the diagnosis. ${ }^{1}$ With advancements in endourology, open or laparoscopic management of ureteric calculi is rarely needed. In one study, it was found that open/laparoscopic management is justified for ureteric calculi with failed endoscopic management and those that are $>3 \mathrm{~cm}^{2}$. The European Association of Urology recommends that ureterolithotomy should be carried out for large impacted stones when management with ESWL or endourological lithotripsy has failed. ${ }^{1}$ Ureterolithotomy is also carried out in centres where latest endourological equipment such as flexible ureteroscope is not available (especially in the low/

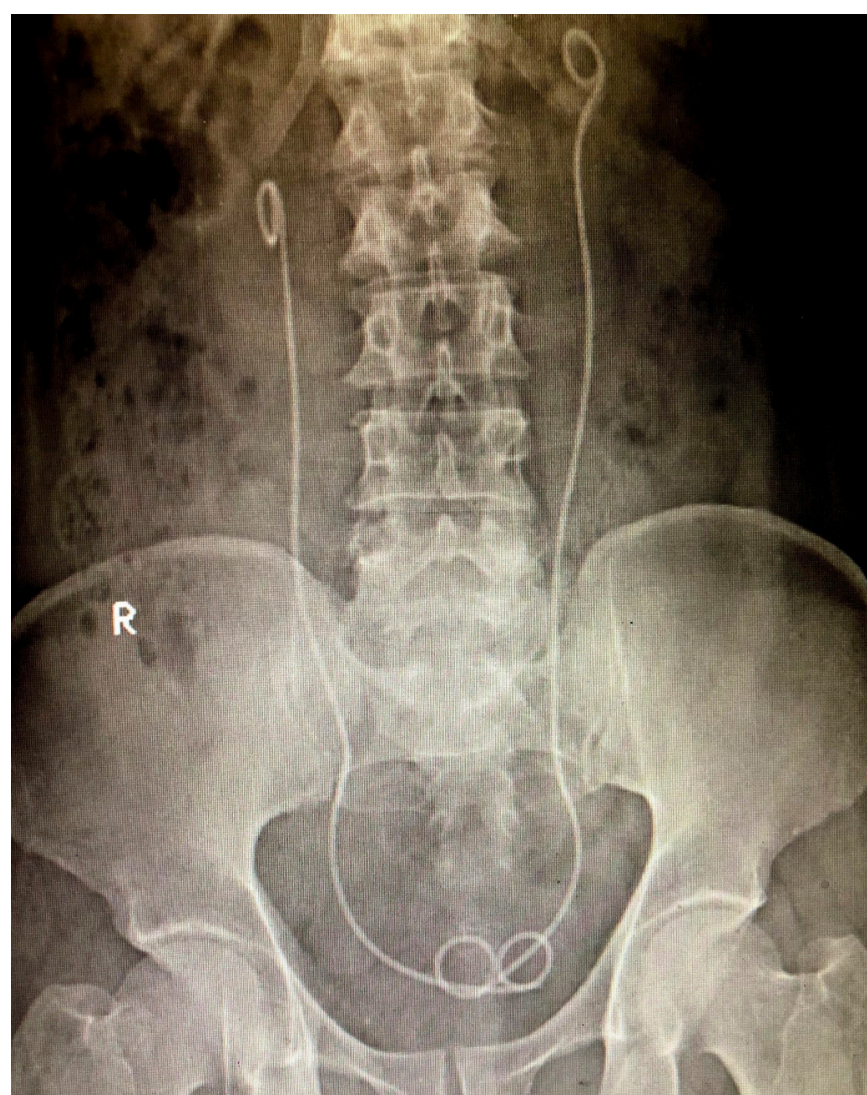

Figure 4 A plain X-ray kidney-ureter-bladder showing complete clearance of calculi in both kidneys.

middle-income world). In a recently conducted meta-analysis, it was found that in properly selected patients with ureteric calculus, minimally invasive ureterolithotomy had better stone-free rates compared with endourological interventions. ${ }^{3}$ In another study, it was found that in the presence of large impacted stones and large stone burden, open ureterolithotomy is a feasible option even in this era of endourology. ${ }^{4}$ Secondary stones usually form in the presence of urinary tract obstruction or infection; the former was responsible in our case. Due to the migratory 'mouse like' secondary calculi, the challenge in our case was to make the patient stone-free in a single setting by us 'cats' that we achieved as mentioned above.

\section{Learning points}

- The indications of ureterolithotomy (open/laparoscopic) are limited in modern urological practice, the ideal candidate being one with large impacted ureteric calculus and failed endourological management.

- In the presence of a dilated proximal urinary tract due to distal obstruction, the resultant secondary calculi may be migratory and difficult to retrieve, for which methods like intraoperatively keeping the patient in reverse-Trendelenburg position and flushing the calculi towards the retrieval site may help.

- While performing ureterolithotomy, it is of utmost importance that the dissection is gentle so that up-migration of calculi is prevented. 
Contributors SP conceived the case report. SP and RJS were major contributors towards writing the manuscript. DS, VS and SP treated the patient and also interpreted the patient data. SP and VS were involved in the review. All authors read and approved the final manuscript.

Funding The authors have not declared a specific grant for this research from any funding agency in the public, commercial or not-for-profit sectors.

Competing interests None declared.

Patient consent Obtained.

Provenance and peer review Not commissioned; externally peer reviewed.

\section{REFERENCES}

1 Türk C, Petřik A, Sarica K, et al. EAU Guidelines on interventional treatment for urolithiasis. Eur Urol 2016;69:475-82.

2 Muslumanoglu AY, Karadag MA, Tefekli AH, et al. When is open ureterolithotomy indicated for the treatment of ureteral stones? Int J Urol 2006;13:1385-8.

3 Kallidonis P, Ntasiotis P, Knoll T, et al. Minimally invasive surgical ureterolithotomy versus ureteroscopic lithotripsy for large ureteric stones: a systematic review and metaanalysis of the literature. Eur Urol Focus 2017;3:554-66.

4 Meitei SK, Lodh B, Khumukcham S, et al. Evaluation of safety and efficacy of open mini-access ureterolithotomy in the era of minimally invasive surgery. Urol J 2014;11:1583-8.

Copyright 2018 BMJ Publishing Group. All rights reserved. For permission to reuse any of this content visit https://www.bmj.com/company/products-services/rights-and-licensing/permissions/

BMJ Case Report Fellows may re-use this article for personal use and teaching without any further permission.

Become a Fellow of BMJ Case Reports today and you can:

- Submit as many cases as you like

- Enjoy fast sympathetic peer review and rapid publication of accepted articles

- Access all the published articles

Re-use any of the published material for personal use and teaching without further permission

For information on Institutional Fellowships contact consortiasales@bmjgroup.com

Visit casereports.bmj.com for more articles like this and to become a Fellow 